Indexed by

\title{
CATALYTIC GASIFICATION OF OIL PALM EMPTY FRUIT BUNCH BY USING INDONESIAN BENTONITE AS THE CATALYST
}

\section{Nabila Aprianti}

Universitas Sriwijaya,

Graduate School,

Doctoral Program of

Environmental Science,

Palembang, Indonesia

\section{Subriyer Nasir}

Universitas Sriwijaya,

Faculty of Engineering,

Chemical Engineering

Department,

Palembang, Indonesia

\section{Muhammad Faizal}

Universitas Sriwijaya,

Faculty of Engineering,

Chemical Engineering

Department,

Palembang, Indonesia

\section{Muhammad Said}

Universitas Sriwijaya,

Faculty of Engineering,

Chemical Engineering

Department,

Palembang, Indonesia
Crossref

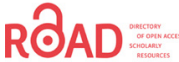

Key words: syngas, waste, bentonite, empty fruit bunch, gasification

Cite article:

Nabila, A., Muhammad, F., Muhammad, S., \& Subriyer, N. [2021]. Catalytic gasification of oil palm empty fruit bunch by using indonesian bentonite as the catalyst. Journal of Applied Engineering Science, 19(2) 334 - 343. DOI:10.5937/jaes0-28781

Online aceess of full paper is available at: www.engineeringscience.rs/browse-issues 


\title{
CATALYTIC GASIFICATION OF OIL PALM EMPTY FRUIT BUNCH BY USING INDONESIAN BENTONITE AS THE CATALYST
}

\author{
Nabila Aprianti ${ }^{1}$, Muhammad Faizal ${ }^{2 *}$, Muhammad Said ${ }^{2}$, Subriyer Nasir ${ }^{2}$ \\ ${ }^{1}$ Universitas Sriwijaya, Graduate School, Doctoral Program of Environmental Science, \\ Palembang, Indonesia \\ ${ }^{2}$ Universitas Sriwijaya, Faculty of Engineering, Chemical Engineering Department, Palembang, Indonesia
}

Oil palm empty fruit bunch (OPEFB) is one of the enormous waste expected to become a renewable energy source. This study aimed to convert OPEFB into syngas through a gasification process using bentonite as a catalyst. The effects of temperature and product gas catalysts were investigated, and the efficiency of the gasification process was summarized. The process has used an updraft gasifier at $350-550^{\circ} \mathrm{C}$ and air as the gasification medium (ER 0.2). The results indicate that syngas can be produced by updraft gasifier. When the temperature increase, the $\mathrm{H}_{2}$ and CO rising. The highest $\mathrm{H}_{2}$ and $\mathrm{CO}$ content of $27.74 \%$ and $20.43 \%$ are obtained at $550^{\circ} \mathrm{C}$ when bentonite applied. $H H V$ and $L H V$ range of 3.38 12.79 $\mathrm{MJ} \mathrm{Nm}^{3}$ and $3.03 \sim 11.58 \mathrm{MJ} / \mathrm{Nm}^{3}$, respectively. The maximum carbon conversion efficiency (CCE) and cold gas efficiency (CGE) reach $85.49 \%$ and $82.34 \%$. Bentonite has been able to increase the concentration of the gas composition especially $\mathrm{H}_{2}$ and $\mathrm{CO}$ and the heating value of syngas.

Key words: syngas, waste, bentonite, empty fruit bunch, gasification

\section{INTRODUCTION}

Energy demand continues to increase worldwide, while fossil fuel reserves continue to decrease. The use of fossil fuel now has an impact on the quality of the environment, which is getting worse due to emissions, especially carbon dioxide. The world faces two problems at once, the fuel-energy crisis and critical environmental issues. In dealing with this, fossil energy is trying to be replaced by renewable energy. According to world energy data, $81.7 \%$ of the world's energy is supplied from fossil energy (oil, coal and natural gas) [1]. Natural gas is cleaner than fossil fuel [2]. Even so, these types of energy will last only in the next 50 years [3].

Synthetic gas or syngas appears as an energy that is needed to meet the world's energy demands. Syngas can be used as fuel, for electricity generation, chemicals, bioethanol, etc. [4]-[6]. Syngas can be applied directly without changing the gas system [7]. The gasification process produces syngas using gasification agents such as air, oxygen, steam, $\mathrm{CO}_{2}$, and/or a combination thereof. Either biomass, coal, and waste fuels can be converted into gas fuels with a high calorific value [8]. Gasification can be carried out at low or high temperatures depending on the selection of process and equipment. Compared to other thermal conversions such as combustion, gasification is an environmentally friendly technology. Gasification produces much less $\mathrm{CO}_{2}$ than combustion, and $\mathrm{SO}_{2}$ is only formed from the initial raw material content of biomass [9].

Apart from the main product, gasification produces tar as a by-product, which must be avoided. Tar formation will cause pipe clogging so that operation and maintenance costs increase [10]. The addition of a catalyst is an effec- tive way to promote tar breaking and reformation of the condensable fraction [11]. To improve the quality of syngas and tar reduction, researchers have applied various types of catalysts. Catalysts commonly used in gasification include alkaline earth metal catalysts [12]-[14], metal-based catalysts [15]-[17], and catalysts minerals (dolomite and olivine) [18]-[20]. In gasification, the catalyst can be used by directly mixing it with raw materials, or it can be placed in the second reactor to break up the tar formed in the main reactor. By all means, the use of the second reactor will increase equipment costs and process handling. The catalyst can increase gas yield and hydrogen concentration [21]-[23]. Sui et al. [24] using cement as a catalyst for water-steam gasification, which succeeded in increasing the $\mathrm{H}_{2}$ content and reducing the tar volume. The $\mathrm{K}_{2} \mathrm{CO}_{3}$ catalyst in pine-sawdust gasification succeeded in lowering the tar volume from $11 \%$ to $2 \%$. Hydrogen increases up to 1.55 times in the catalyst to biomass ratio of 2, using $\mathrm{CaO}$ as a catalyst [25]. Likewise, when the dolomite catalyst rose from 3 to $12 \mathrm{wt} \%$, the hydrogen increased from 52.9 to $55.5 \mathrm{~g} / \mathrm{kg}$ of fuel [18].

Natural mineral catalysts are becoming widely used because they are cheap and abundant. Bentonite is a clay mineral rock that is abundant in Indonesia. Its use is mostly in the treatment of wastewater and adsorbents. Bentonite has different characteristics in each region, which causes its use as a particular medium that needs to be studied further. For example, bentonite from Africa (African bentonite) is widely used as a remediation [26] and removal process [27], and bentonite from Nigeria (Nigerian bentonite) is used in the mud formulation drilling process [28], [29]. Inclusion of the origin of natural bentonite needs to be done to identify the difference both in terms of its utilization and the location where the ben- 
tonite was taken. In Indonesia, bentonite has been used for adsorption processes [30], wastewater treatment [31], and catalytic degradation [32].

Bentonite is used as the catalyst in pyrolysis, cracking, and biodiesel processes. According to the results from Kumar and [33], bentonite mostly consisted of $\mathrm{SiO}_{2}$ and $\mathrm{Al}_{2} \mathrm{O}_{3}(52.55 \%$ and $15.34 \%)$. Similarly, Ro et al. [34], bentonite with $\mathrm{SiO}_{2}$ and $\mathrm{Al}_{2} \mathrm{SO}_{3}$, is used as the catalyst for the in-situ pyrolysis process, which produces bio-oil with high selectivity hydrocarbons. According to Sewu et al. [35], bentonite increases the bio-oil yield in the pyrolysis process. The presence of bentonite significantly affects the reaction rate as well as the quality of the condensation fraction [36]. Liquid fuels resulting from catalytic cracking by Kar et al. achieved $98.64 \%$ of yield with $4 \%$ of the catalyst [37]. In the transesterification process, bentonite removes water and increases the methanolysis process. The by-product of biodiesel, soap, which is avoided, decreases when the bentonite is applied [38].

In Indonesia, biomass as a gasification feedstock is very efficient in the sustainability and use of clean energy. The palm oil industry growing rapidly in Indonesia produces two categories of waste, namely waste from plantations and waste from crude palm oil (CPO) processing plants [39]. One of the CPO industrial wastes, oil palm empty bunches (OPEFB), if used as gasification feedstock, will increase its use-value. For every ton of CPO produced, there will be around 5 tons of solid waste from oil palm biomass, consisting of oil palm empty bunches (OPEFB), palm kernel shells (PKS), and palm mesocarp fibers (PMS). From 1-ton fresh fruit bunches (FFB) which is ready to be processed in industrial $C P O$, there will be approximately 23\% OPEFB. With a total FFB in 2019 of 42.7 million tons, the number of OPEFB is approximately 8.97 million tons [40]. Evidently, according to Ariffin et al. [41], the calorific value of OPEFB is $16 \mathrm{MJ} / \mathrm{Kg}$, so OPE$\mathrm{FB}$ is feasible to convert into syngas though it is lower than coal.

Utilization and value addition to OPEFB through the gasification process is very promising in supporting the achievement of sustainable energy and environment. Research on OPEFB gasification has been conducted by several researchers in the last five years [42]-[44] and still developed to increase the quality. To the best of our knowledge, both Indonesian bentonite and natural bentonite from other areas have not been used comprehensively on the gasification process particularly OPEFB gasification. Although its effects have been tested as adsorbents and catalysts in wastewater treatment and pyrolysis processes, further and depth studies are needed on the application of the gasification process. This project tries to produce to produce syngas with low $\mathrm{CO}_{2}$ levels from OPEFB gasification. The effect of gasification parameters and bentonite on the gasification process and efficiency will be investigated.

\section{MATERIALS AND METHODS}

\section{Feedstock}

Oil palm empty bunches (OPEFB) are obtained from the CPO industry in South Sumatra, Indonesia. OPEFB was collected and then separated from the bunches and dried under the sun for \pm 48 hours (Fig. 1). Pre-drying is required for OPEFB because of its high moisture content. High moisture content has an impact on the low heating value of the gas [45]. After drying, OPEFB is chopped manually with a size of $3 \times 3 \mathrm{~cm}$ to facilitate the loading into the gasifier and within the range of recommendation for updraft gasifier [46]. OPEFB characteristics are known through proximate and ultimate analysis related to its use as an energy source. Proximate analysis is based on mass reduction using a thermogravimetric analyzer (TGA PT1000), referring to the method of the American Society for Testing and Materials (ASTM) D 3172-3175. Meanwhile, the ultimate analysis was performed using the CHONS analyzer (Thermo Scientific Flash 2000), referring to ASTM D5373. The calorific value (gross calorific value) of OPEFB or known as HHV is measured using a bomb calorimeter (Parr 6200 calorimeter) according to ASTM D 5865-2013. In addition, in this study, the OPEFB lignocellulose content was also analyzed using high-performance liquid chromatography (RIGOL L-3000 HPLC).

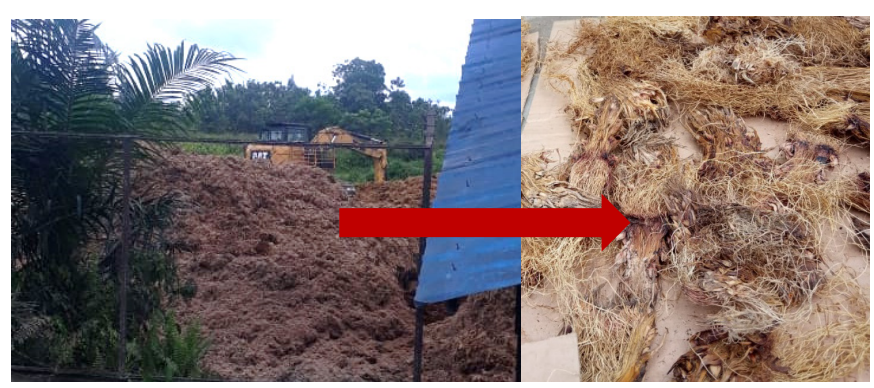

Figure 1: Samples of OPEFB

\section{Bentonite characterization}

To improve the performance of natural bentonite (NB) as a gasification catalyst, activation was carried out. Bentonite was heated in the furnace at $400{ }^{\circ} \mathrm{C}$ for 3 hours and stored in the desiccator to be cooled for 24 hours. Characterization of bentonite aimed to determine the changes in the structure, functional groups, and morphology of bentonite after thermal activation. Characterization involved the X-Ray diffraction (XRD) method using the Rigaku Miniflex 600 X-Ray diffractometer, Fourier Transform Infra-Red (FTIR) using the Thermo Scientific Nicolet iS10 FT-IR Spectrometer and Scanning Electron Microscope (SEM) using the JEOL-JSM-6510 LA at the magnification of 20,000 times. Furthermore, the bentonite that has been activated used as a direct catalyst is called natural bentonite thermal activated (NBTA). 


\section{Gasification equipment and process}

An updraft gasifier apparatus was made from stainless steel (SS316) with electrical heater outside the reactor. The reaction temperature was controlled by automatically control panel equipped with K-type thermocouple in the top and bottom of the gasifier. OPEFB and catalyst were mixed in the reactor before by mixer connected to the control system. To avoid additional costs, air is used a gasification agent instead of pure oxygen. Air is fed into the gasifier via a compressor. The flow rate of the gasification agent is based on the equivalent ratio (ER) of 0.2 . Raw material and catalyst were placed into the gasifier, and the reactor is set to the desired temperature of $350-550{ }^{\circ} \mathrm{C}$. Subsequent to the steady-state condition reached, gas was sampled in the sample point after through the cooling system. In order to know the composition, gas was analyzed using Shimadzu 2014 gas chromatography. Meanwhile, the liquid product known as tar was stored in the tube separately. Flow diagram of the gasification apparatus and process has been re-illustrated according to previous work (Fig. 2) [44].

\section{Syngas analysis}

Performance and efficiency of syngas in the gasification process are determined by determining the calorific value (HHV and LHV), carbon conversion efficiency (CCE), cold gas efficiency (CGE), and the ratio of combustible gas (Eq 1-5) [47]-[49].

$$
\begin{aligned}
& H H V_{\text {gas }}=\left((30.18 \times C O)+\left(30.52 \times H_{2}\right)+\left(95 \times C_{4}\right)\right) \times \\
& \times 4.1868\left(M J / N M^{3}\right)
\end{aligned}
$$

$$
\begin{aligned}
& L H V_{\text {gas }}=\left((30 \times C O)+\left(25.7 \times H_{2}\right)+\left(85.4 \times C_{4}\right)\right) \times \\
& \times 4.2\left(M J / N M^{3}\right) \\
& \operatorname{CCE}(\%)=\frac{\text { Carbon content in gas }(\%)}{\text { Carbon content in OPEFB }(\%)} \times 100 \\
& C G E(\%)=\frac{L H V_{\text {gas }}}{L H V_{\text {OPEFB }}} \times 100 \\
& \frac{C G}{N C G} \text { ratio }=\frac{\text { Combustible gas }}{\text { Noncombustibel gas }}
\end{aligned}
$$

\section{RESULTS AND DISCUSSION}

\section{OPEFB characteristics}

Proximate and ultimate analysis on OPEFB has been carried out to determine the characteristics of the material related to its use in energy conversion (Table 1). The analysis results were compared with other OPEFB from previous work [50]-[52]. The fixed carbon of OPEFB in this study was higher than OPEFB from other studies, namely $23.75 \%$. This correlates to high carbon content. Fixed carbon is influenced by the ash content, water, and volatile matter of the raw material.

The volatile matter of OPEFB is much lower compared to similar biomass from other works. Likewise, when compared with other biomass such as corncob [53], sugarcane [54], rice husk [55], pine sawdust [56], and coconut shell [56]. Biomass has a higher volatile matter value in biomass than coal, which indicates that biomass is easier to convert to gas. The OPEFB from this work revealed

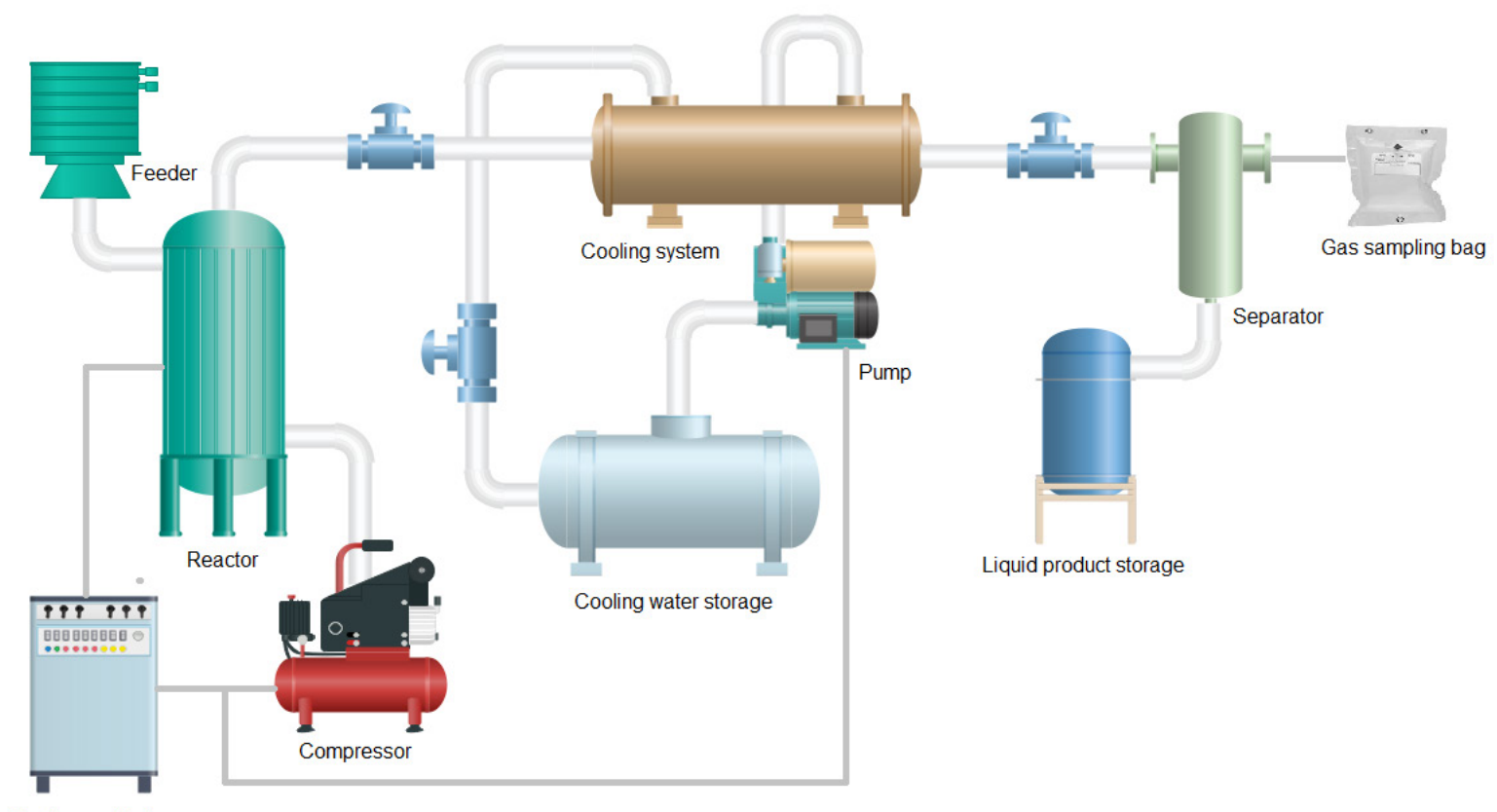

System controller

Figure 2: Flow Diagram of OPEFB Catalytic Gasification 
the highest content of ash compared with other same types, especially compared to the result of Isworo et al. [50]. Ash can degrade the fixed carbon content so that the calorific value also decreases. Ash content in this study was $16.81 \%$.

On the basis of the elemental analysis, OPEFB contains $32.56 \% \mathrm{O}, 46.25 \% \mathrm{C}, 4.14 \% \mathrm{H}, 0.18 \% \mathrm{~N}$, and $0.07 \% \mathrm{~S}$, respectively. Compared to others, OPEFB in this study has the lowest oxygen, but rich in carbon content. This value has a positive effect on HHV because of lower oxygen concentrations (the calorific value of OPEFB decreased in the presence of $\mathrm{C}-\mathrm{O}$ bonds). OPEFB in this work indicated the lowest sulfur content of all OPEFB from literature (Table 1). Sulfur and nitrogen are present in minimal amounts in OPEFB. Sulfur and nitrogen are the sources of the formation of $\mathrm{SO}_{x}$ and $\mathrm{NO}_{x}$ gases in syngas when used as fuel, but because of their small amount, they can be categorized as safe for the environment. OPEFB has $16.47 \mathrm{MJ} / \mathrm{kg}$ of HHV. It is still in the HHV OPEFB range.

\section{Bentonite characteristics}

Bentonite was collected from Sarolangun, Indonesia. To evaluate the performance of bentonite as a catalyst, the analysis of its characteristics has been carried out and illustrated by Fig. 3-4. Bentonite was activated for increasing the catalytic activity. Based on XRD spectra, the main degree appeared at $5^{\circ}, 20^{\circ}$, and $26^{\circ}$ that was indicated the presence of main characteristics of bentonite and montmorillonite [57]. Hereinafter, natural bentonite contains impurities in the presence of quartz around $27^{\circ}$ [58]. After activated, several components lost which are shown by the decrease of the peak. Some peaks disappeared and replaced by the other new peak.

The FTIR spectra showed the different changes of activated bentonite from non-activated bentonite rather inconspicuous. The main structure of bentonite was observed at bands of $470,532,911$, and $1033 \mathrm{~cm}^{-1}$. At bands of $3626 \mathrm{~cm}^{-1}$ and $911 \mathrm{~cm}^{-1}$, there were presented of Si-OH and Al-OH-Al stretching respectively [59]. The

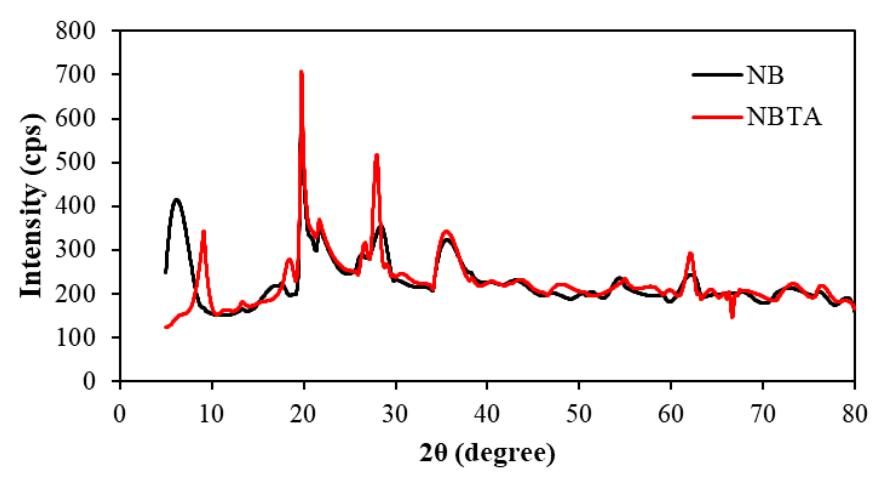

(a)

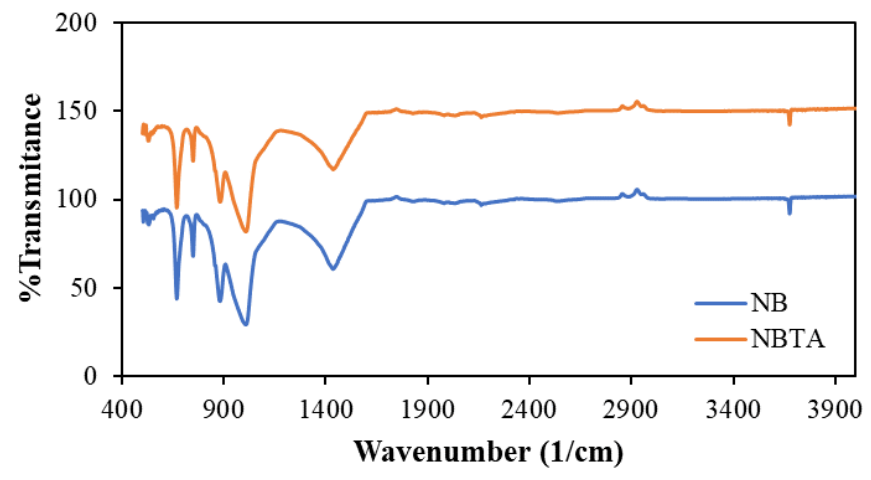

(b)

Figure 3: XRD (a) and FTIR (b) Spectra of NB and NBTA

stretching vibration at $1033 \mathrm{~cm}^{-1}$ emerged as a strong band $\mathrm{Si}-\mathrm{O}-\mathrm{Si}$. [60]. At wavenumbers of $3448 \mathrm{~cm}^{-1}$ and $1635 \mathrm{~cm}^{-1}$, there were strong bands of the $\mathrm{O}-\mathrm{H}$ group and bending vibration of bentonite [61].

SEM analysis results (Fig. 4) show that the surface morphology of natural bentonite and activated bentonite is slightly different. Bentonite displayed larger denser sheets in natural bentonite, whereas the surface in the activated bentonite was in the form of sparse and smooth sheets of various sizes. SEM observations revealed that bentonite particle has a dominant size of $1 \mu \mathrm{m}$. There were quite a lot of cracks on both surfaces, according to

Table 1: Characteristic of OPEFB by Proximate and Ultimate Analysis

\begin{tabular}{|c|c|c|c|c|}
\hline Parameter & This study & Isworo et al.[50] & Nyakuma et al.[51] & Monir et al.[52] \\
\hline Proximate analysis (wt\%) & & & & \\
\hline Ash content & 16.81 & 1.99 & 6.36 & 7 \\
\hline Volatile matter & 59.44 & 72.8 & 81.63 & 18.5 \\
\hline Fixed carbon & 23.75 & 20.42 & 12.37 & 15.58 \\
\hline Calorific value (MJ/Kg) & 16.47 & 17.37 & 17.84 & \\
\hline Elemental analysis (wt\%) & & & & 42.33 \\
\hline C & 46.25 & 43.8 & 45.23 & 5.28 \\
\hline H & 4.14 & 6.2 & 6.46 & 1.46 \\
\hline N & 0.18 & 0.4 & 1.25 & 50.84 \\
\hline O & 32.56 & 44.4 & 47.84 & 0.08 \\
\hline S & 0.07 & 0.08 & 0.14 & \\
\hline
\end{tabular}




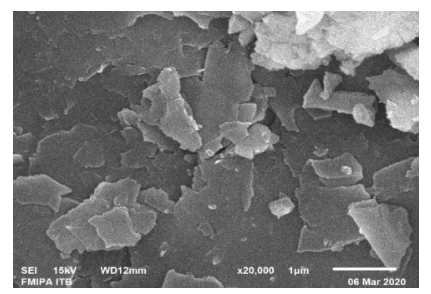

(a)

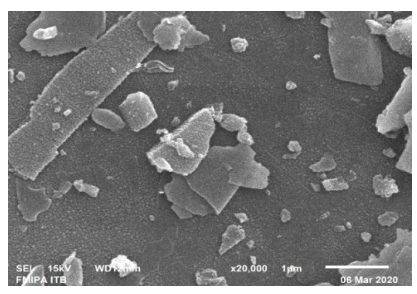

(b)
Figure 4: Morphology of NB (a) and NBTA (b)

the SEM analysis. After the activation process, bentonite produced a more irregular surface. Indonesian bentonite has similar properties to bentonite from other countries, which is dominated by $\mathrm{SiO}_{2}$ and $\mathrm{Al}_{2} \mathrm{O}_{3}$.

\section{Syngas composition}

The composition of gas products from OPEFB gasification using bentonite as a catalyst is presented in Fig. 5 . The gas product mainly comprises $\mathrm{H}_{2}, \mathrm{CO}$ and $\mathrm{CH}_{4}$ with minor amounts of $\mathrm{CO}_{2}$ and $\mathrm{O}_{2}$. The effect of temperature on gas composition is quite large corresponding to the increasing $\mathrm{H}_{2}$ and $\mathrm{CO}$ content. However, there was increasing in $\mathrm{CO}_{2}$ content but is shown in the small amount. In this work, the highest of $\mathrm{H}_{2}$ content was $27.74 \%$, while the highest of $\mathrm{CO}$ was $20.43 \%$ achieved at $550^{\circ} \mathrm{C}$ in the presence of bentonite. The $\mathrm{H}_{2}$ and $\mathrm{CO}$ components increased along with the increase in temperature. Another gas product, $\mathrm{CH}_{4}$, exhibited the same phenomenon when the temperature above 450 . The $\mathrm{CH}_{4}$ content increased significantly. The increase in $\mathrm{CH}_{4}$ is affected by the methanation reaction in the reduction zone. This is in line with another previous gasification study [62].

Syngas consists of two main components, $\mathrm{H}_{2}$ and $\mathrm{CO}$. The use of hydrogen is widely used in pure form, or $\mathrm{H}_{2} / \mathrm{CO}$ is greater. Fig. 6 shows the gas ratio in the specific of $\mathrm{H}_{2} / \mathrm{CO}$ and combustible gas of OPEFB gasification. Both non-catalytic and catalytic gasification, the highest $\mathrm{H}_{2} / \mathrm{CO}$ ratio, were obtained at $350^{\circ} \mathrm{C}$ of 2.33 and 1.90 . The product gas from OPEFB using bentonite contained $\mathrm{H}_{2}$ as the dominant component resulting in the lower ratio level. The temperature did not show a substantial effect on the ratio of $\mathrm{H}_{2} / \mathrm{CO}$, so the value was not relatively stable on OPEFB gasification, along with the increase of temperature using bentonite as a catalyst. The ratio range was 1.33 1.90. Overall, the ratio showed $>1$, which indicates that the syngas produced is suitable for fuel [7].

Since the oxygen is used as a gasification agent, $\mathrm{O} 2$ and $\mathrm{N}_{2}$ remain in the product gas. Because of syngas will use as fuel, we tried to figure out the comparison between the combustible gas and non-combustible gas. It was found that the product gas from OPEFB, which used bentonite shows the highest CG/NCG ratio in the value of 9.72 . The CG/NCG ratio was affected by the combustible gas in the syngas, comprised of $\mathrm{CO}, \mathrm{H}_{2}$ and $\mathrm{CH}_{4}$. Unlike the $\mathrm{H}_{2} / \mathrm{CO}$ ratio, the CG/NCG ratio increased along with the increase of gasification temperature.

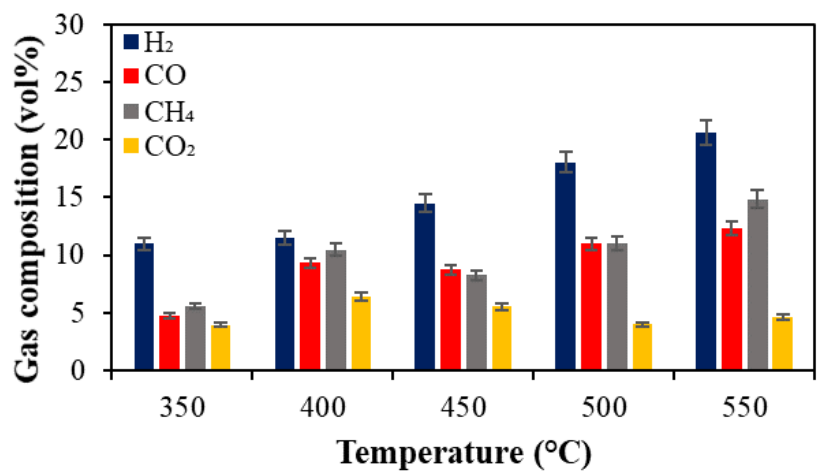

(a)

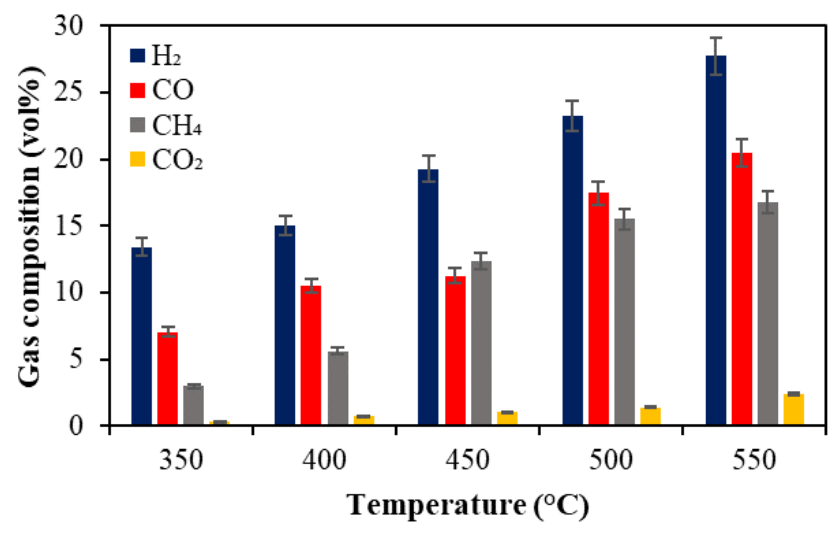

(b)

Figure 5: Gas Composition of OPEFB Gasification for Non-catalytic (a) and Catalytic (b)

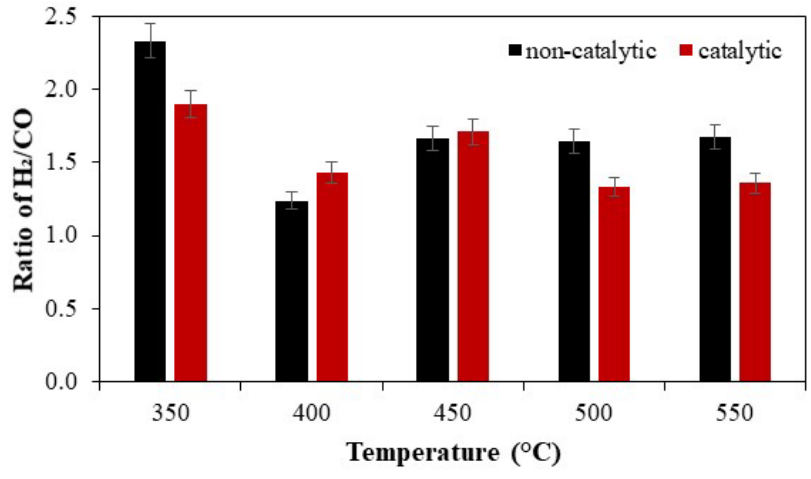

(a)

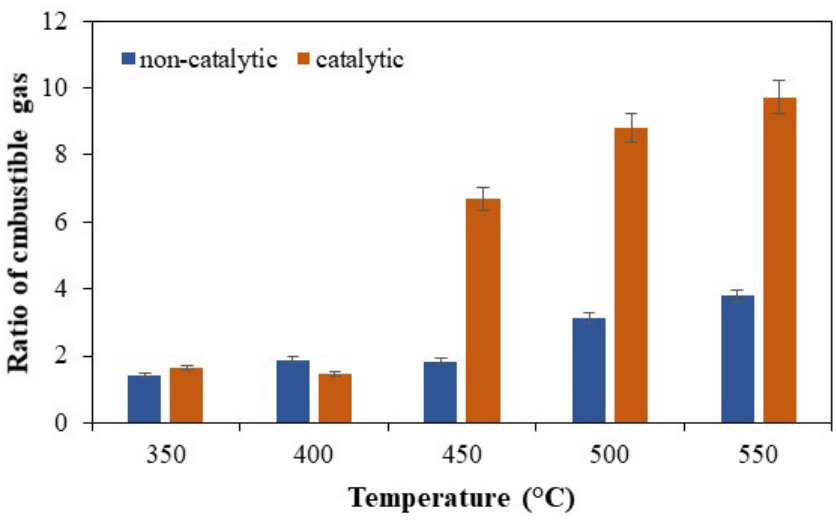

(b)

Figure 6: Ratio of $\mathrm{H}_{2} \mathrm{CO}$ (a) and Combustible Gas (b) 


\section{Effect of bentonite on syngas production}

Bentonite affects the concentration of syngas composition and yield. It can be seen that $\mathrm{H}_{2}$ and $\mathrm{CO}$ increased significantly after the addition of bentonite in the same range of temperature (Fig 5). Not only that, but the $\mathrm{CO}_{2}$ concentration has also decreased. This is due to the $\mathrm{Si}^{2}$ and $\mathrm{Al}$ content in bentonite, which increases the rate of the conversion reaction of complex compounds in OPEFB into low molecular gases. $\mathrm{SiO}_{2}$ and $\mathrm{Al}_{2} \mathrm{O}_{3}$ make bentonite a good heat conductor for raw materials [63]. The existence of the acidic site of $\mathrm{Al}_{2} \mathrm{O}_{3}$ dan $\mathrm{SiO}_{2}$ from bentonite turn the route of catalytic activity to hydrocarbon cracking [37]. The strong acidic site on bentonite enhanced catalytic cracking more inside [64].

Since bentonite was used directly in conjunction with OPEFB, it was judged appropriate and successful. The presence of $12.5 \mathrm{wt} \%$ of bentonite is based on previous studies using other types of catalysts, but it is less than $10 \%$ nor bentonite on other work. With the hope that passing this portion can have a significant impact, the application will occur in the presence of bentonite. Apart from $\mathrm{H}_{2}$ and $\mathrm{CO}$, the concentration of $\mathrm{CH}_{4}$ also increased. The increase in the $\mathrm{H}_{2}$ and $\mathrm{CO}$ components also leads to the formation of $\mathrm{CH}_{4}$ through the methanation reaction. During the reaction, there was an acid-base reaction from the Bronsted side. The exchange of $\mathrm{H}^{+}$cations from bentonite to OPEFB causes catalytic cracking. Hydrogen is also formed in the presence of an $\mathrm{H}^{+}$donor from bentonite to the $\mathrm{C}-\mathrm{H}$ bond of hydrocarbons in OPEFB. The catalytic activity of bentonite is associated with the available Brønsted sites on the catalyst [65].

\section{Efficiency of gasification}

In this study, the gasification efficiency consisted of carbon conversion efficiency (CCE), cold gas efficiency (CGE) and calorific value of gas (LHV and HHV) (Fig. 7). The HHV and LHV change in the range from 3.78 to $12.79 \mathrm{MJ} / \mathrm{Nm}^{3}$ and 3.39 to $11.58 \mathrm{MJ} / \mathrm{Nm}^{3}$ successively when bentonite was used. The heating value of original OPEFB gasification was in the range of 4.22-10.10 MJ/ $\mathrm{Nm}^{3}$ and 3.78-9.11 MJ/Nm${ }^{3}$ for HHV and LHV. The heating value is influenced by the gas composition of $\mathrm{H}_{2}, \mathrm{CO}$, and $\mathrm{CH} 4$. Because the content of these three gases increased with increasing temperature, the HHV and LHV increased as well. The HHV and LHV of syngas increase when bentonite is added because it is related to the composition of the gas that has been obtained.

The efficiency of gasification is known by calculating the carbon content in feedstock and gas and comparing the LHV gas with the LHV feedstock [66]. Carbon conversion efficiency (CCE) of OPEFB gasification showed the increment together with rising the temperature, so does the cold gas efficiency (CGE) (Fig. 8). The maximum CCE and CGE were $85.49 \%$ and $82.34 \%$ at $550 \%$. Cold gas efficiency is affected by increasing $\mathrm{CO}, \mathrm{H}_{2}$, and $\mathrm{CH}_{4}$ and increasing temperature [67]. Because OPEFB is wet

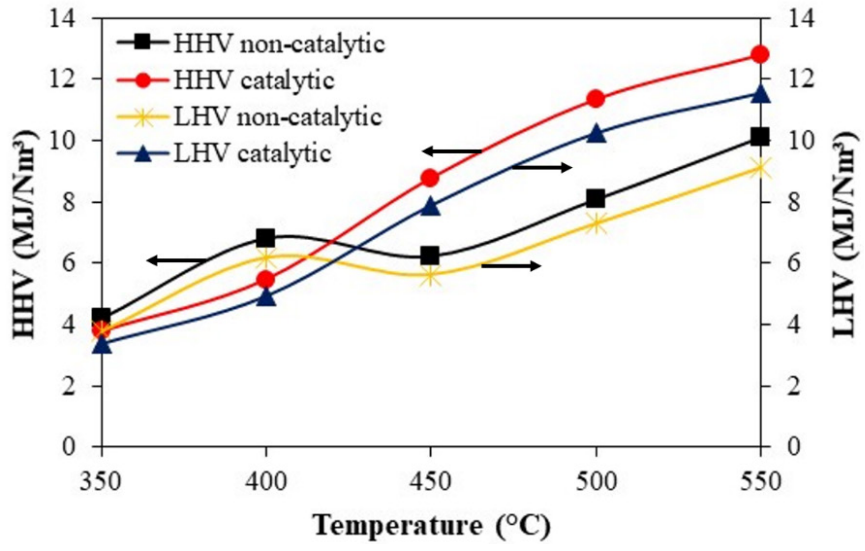

Figure 7: Syngas Heating Value of OPEFB Gasification

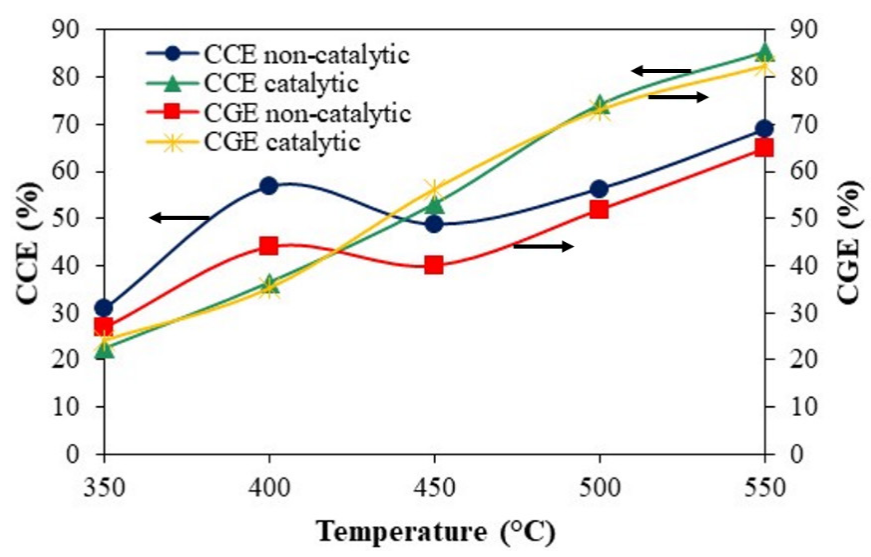

Figure 8: The Efficiency of OPEFB Gasification

biomass, gasification efficiency tends to be small if it is not anticipated by pre-drying [68].

\section{CONCLUSION}

The oil palm empty fruit bunch was successfully converted to syngas by gasification in an updraft gasifier. The gasification is mainly affected by temperature. The results show that the higher component of gas, the higher temperature needed. At $550^{\circ} \mathrm{C}, \mathrm{H}_{2}$ and $\mathrm{CO}$ contents are $27.74 \%$ and $20.43 \%$ with the addition of natural bentonite. As a fuel, the ratio of $\mathrm{H}_{2} / \mathrm{CO}$ is achieved 1.33-1.90. When the gasification temperature increased, the heating value of the gas product increases significantly from 3.38 to $12.79 \mathrm{MJ} / \mathrm{Nm}^{3}$ for $\mathrm{HHV}$ and 3.39 to $11.58 \mathrm{MJ} / \mathrm{Nm}^{3}$ for LHV. Although the $\mathrm{H}_{2}$ and $\mathrm{CO}$ content relatively low, CCE and CGE succeed reach above $80 \%$ of $85.49 \%$ and $82.34 \%$ in succession.

\section{ACKNOWLEDGEMENTS}

This work was supported by PMDSU scholarship (Grant No. 270/SP2H/LT/DRPM/2019 and 0234/UN9/SB3. LP2M.PT/2019). The authors were also grateful to PT. Pupuk Sriwidjaja Palembang for gas analysis during this research. 


\section{REFERENCES}

1. Zhang, Y., Sivakumar, M., Yang, S., Enever, K., Ramezanianpour, M. (2017). Application of solar energy in water treatment processes: A review. Desalination, 428, 116-145, DOI: 10.1016/j.desal.2017.11.020.

2. Xu, X., Chen, Y. (2016). Air emissions from the oil and natural gas industry, International Journal of Environmental Studies. 73, 3, 422-436, DOI: 10.1080/00207233.2016.1165483.

3. Erickson, P., Lazarus, M. (2018). Would constraining US fossil fuel production affect global $\mathrm{CO} 2$ emissions? A case study of US leasing policy. Climate Change, 150, 1-2, 29-42, DOI: 10.1007/s10584018-2152-z.

4. Darmawan, A., Ajiwibowo M. W., Biddinika, M. K, Tokimatsu, K., Aziz, M. (2019). Black liquor-based hydrogen and power co-production: Combination of supercritical water gasification and syngas chemical looping. Applied Energy, 252, 113446, DOI: 10.1016/j.apenergy.2019.113446.

5. AlNouss A., McKay, G., Al-Ansari, T. (2020). Production of syngas via gasification using optimum blends of biomass. Journal of Cleaner Production, 242, 118499, DOI: 10.1016/j.jclepro.2019.118499.

6. Paulino, R. F. S., Essiptchouk, A. M., Silveira, J. L. (2020). The use of syngas from biomedical waste plasma gasification systems for electricity production in internal combustion: Thermodynamic and economic issues. Energy, 199, DOI: 10.1016/j.energy.2020.117419.

7. Tamosiunas, A., Valatkevicius, P., Grigaitiene, V., Valincius, V., Striugas, N. (2016). A cleaner production of synthesis gas from glycerol using thermal water steam plasma. Journal of Cleaner Production, 130, 187-194, DOI: 10.1016/j.jclepro.2015.11.024.

8. Tabakaev, R., Shanenkov, I., Kazakov, A., Zavorin, A. (2017). Thermal processing of biomass into high-calorific solid composite fuel. Journal of Analytical and Applied Pyrolysis, 124, 94-102, DOI: 10.1016/j. jaap.2017.02.016.

9. Khan, Z., Yusup, S., Aslam, M., Inayat, A., Shahbaz, M., Vaqvi, S. R., Farooq, R., Watson, I. (2019). NO and $\mathrm{SO} 2$ emissions in palm kernel shell catalytic steam gasification with in-situ $\mathrm{CO} 2$ adsorption for hydrogen production in a pilot-scale fluidized bed gasification system. Journal of Cleaner Production, 236, 117636, DOI: 10.1016/j.jclepro.2019.117636.

10. Qiu, P., Du, C., Liu, L., Chen, L. (2018). Hydrogen and syngas production from catalytic steam gasification of char derived from ion-exchangeable $\mathrm{Na}$ and Ca-loaded coal. International Journal of Hydrogen Energy, 43, 27, 12034-12048, DOI: 10.1016/j. ijhydene.2018.04.055.
11. Tan, R. S., Alir, A., Mohamad, S. A., Md Isa, K., Tuan Abdullah, T. A. (2019). Ni-based catalysts for steam reforming of tar model derived from biomass gasification. E3S Web Conference, 90, 01015, DOI: 10.1051/e3sconf/20199001015.

12. Feng, D., Zhao, Y., Zhang, Y., Xu, H., Zhang, L., Sun, S. (2018). Catalytic mechanism of ion-exchanging alkali and alkaline earth metallic species on biochar reactivity during $\mathrm{CO} 2 / \mathrm{H} 2 \mathrm{O}$ gasification. Fuel, 212, 523-532, DOI: 10.1016/j.fuel.2017.10.045.

13. Zubek, K., Czerski, G., Porada, S. (2018). Determination of optimal temperature and amount of catalysts based on alkali and alkaline earth metals for steam gasification process of bituminous coal. Thermochimica Acta, 665, 60-69, DOI: 10.1016/j. tca.2018.05.006.

14. Spiewak, K., Czerski, G., Porada, S. (2020). Effect of $\mathrm{K}, \mathrm{Na}$ and $\mathrm{Ca}$-based catalysts on the steam gasification reactions of coal. Part I: Type and amount of one-component catalysts. Chemical Engineering Science, 229, 116024, DOI: 10.1016/j. ces.2020.116024.

15. Cavattoni, T., Garbarino, G. (2017). Catalytic abatement of biomass tar: a technological perspective of Ni-based catalysts. Rendiconti Lincei, 28, 69-85, DOI: 10.1007/s12210-017-0609-Z.

16. Liu, X., Zhang, Y., Nahil, M. A., Williams, P. T., Wu, C. (2017). Development of Ni- and Fe- based catalysts with different metal particle sizes for the production of carbon nanotubes and hydrogen from thermo-chemical conversion of waste plastics. Journal of Analytical and Applied Pyrolysis, 125, 32-39, DOI: 10.1016/j.jaap.2017.05.001.

17. Abedi, A., Dalai, A. K. (2019). Steam gasification of oat hull pellets over Ni-based catalysts: Syngas yield and tar reduction. Fuel, 254, 115585, 2019, DOI: 10.1016/j.fuel.2019.05.168.

18. Ma, X., Zhao, X., Gu, J., Shi, J. (2019). Co-gasification of coal and biomass blends using dolomite and olivine as catalysts. Renewable Energy, 132, 509-514, DOI: 10.1016/j.renene.2018.07.077.

19. Hervy, M., Olcese, R., Bettahar, M. M., Mallet, M., Renard, A., Maldonado, L., Remy, D., Mauviel, G., Dufour, A. (2019). Evolution of dolomite composition and reactivity during biomass gasification. Applied Catalysis A: General., 572, 97-106, 2019, DOI: 10.1016/j.apcata.2018.12.014.

20. Islam, M. W. (2020). A review of dolomite catalyst for biomass gasification tar removal. Fuel, 267, 117095, DOI: 10.1016/j.fuel.2020.117095. 
21. Suhaj, P., Haydary, J., Husar, J., Steltenpohl, P., Supa, I. (2019). Catalytic gasification of refuse-derived fuel in a two-stage laboratory scale pyrolysis/ gasification unit with catalyst based on clay minerals. Waste Management, 85, 1-10, DOI: 10.1016/j. wasman.2018.11.047.

22. Shang, S., Guo, C., Lan, K., Li, Z., He, W., Qin, Z., $\mathrm{Li}$, J. (2020). Hydrogen-rich syngas production via catalytic gasification of sewage sludge and wheat straw using corn stalk char-supported catalysts. BioResources, 15, 2, 4294-4313, DOI: 10.15376/ biores.15.2.4294-4313.

23. Liao, Y., Deng, F., Xiao, B. (2019). Hydrogen-rich gas production from catalytic gasification of pine sawdust over Fe-Ce/olivine catalyst. International Journal of Energy Research, 43, 13, 7486-7495, 2019, doi: 10.1002/er.4781.

24. Sui, M., G. Li, Guan,Y. L., Li, C. M., Zhou, R. Q., Zarnegar, A. M. (2019). Hydrogen and syngas production from steam gasification of biomass using cement as catalyst. Biomass Conversion and Biorefinery, 10, 119-124, DOI: 10.1007/s13399-01900404-6.

25. Zho, L., Yang, Z., Tang, A., Huang, H., Wei, D., Yu, E., Lu, W. (2019). Steam-gasification of biomass with $\mathrm{CaO}$ as catalyst for hydrogen-rich syngas production. Journal of the Energy Institute, 95, 6, 16411646, DOI: 10.1016/j.joei.2019.01.010.

26. Masindi, V., Gitari, M. W., Tutu, H., DeBeer, M. (2015). Efficiency of ball milled South African bentonite clay for remediation of acid mine drainage. Journal of Water Process Engineering, 8, 227-240, 2015, DOI: 10.1016/j.jwpe.2015.11.001.

27. Masindi, V., Ramakokovhu, M. M. (2020). The performance of thermally activated and vibratory ball milled South African bentonite clay for the removal of chromium ions from aqueous solution. Materials Today: Proceedings, DOI: 10.1016/j.matpr.2020.05.490.

28. Afolabi, R. O., Orodu, O. D., Efeovbokhan, V. E. (2017). Properties and application of Nigerian bentonite clay deposits for drilling mud formulation: Recent advances and future prospects. Applied Clay Science, 143, 39-49, DOI: 10.1016/j. clay.2017.03.009.

29. Afolabi, R. O., Ogunkunle, T. F., Olabode, O. A., Yusuf, E. O. (2018). Dataset on the beneficiation of a Nigerian bentonite clay mineral for drilling mud formulation. Data Brief, 20, 234-241, DOI: 10.1016/j. dib.2018.07.071.

30. Warsono, H. R. S., Kurniawan, W., Hinode, H. (2018). Utilization of modified Indonesia natural bentonite for dye removal. ASEAN Journal of Chemical Engineering, 18, 2, 13-21, DOI: 10.22146/ajche.49532.
31. Rahardjo, A. K., Susanto, M. J. J., Kurniawan, A., Indraswati, N., Ismadji, S. (2011). Modified Ponorogo bentonite for the removal of ampicillin from wastewater. Journal of Hazardous Materials, 190, 1-3, 1001-1008, DOI: 10.1016/j.jhazmat.2011.04.052.

32. Pradisty, N. A., Sihombing, R., Howe, R. F., Krisnandi, Y. K. (2017). Fe(III) oxide-modified Indonesian bentonite for catalytic photodegradation of phenol in water. Makara Journal of Science, 21, 1, 25-33, DOI: $10.7454 / \mathrm{mss} . v 21 \mathrm{i} 1.7534$.

33. Kumar, A., Lingfa, P. (2020). Sodium bentonite and kaolin clays: Comparative study on their FT-IR, XRF, and XRD. Materials Today: Proceedings, 22, 737742, DOI: 10.1016/j.matpr.2019.10.037.

34. Ro, D., Shafaghat, H., Jang, S. H., Lee, H. W., Jung, S. C., Jae, J., Cha, J. S., Park, Y. K. (2019). Production of an upgraded lignin-derived bio-oil using the clay catalysts of bentonite and olivine and the spent FCC in a bench-scale fixed bed pyrolyzer. Environmental Research, 172, 658-664, DOI: 10.1016/j.envres.2019.03.014.

35. Sewu, D. D., Lee, D. S., Tran, H. N., Woo, S. H. (2019). Effect of bentonite-mineral co-pyrolysis with macroalgae on physicochemical property and dye uptake capacity of bentonite/biochar composite. Journal of the Taiwan Institute of Chemical Engineers, 104, 106-113, DOI: 10.1016/j.jtice.2019.08.017.

36. Panda, A. K. (2018). Thermo-catalytic degradation of different plastics to drop in liquid fuel using calcium bentonite catalyst. International Journal of Industrial Chemistry, 9, 2, 167-176, DOI: 10.1007/ s40090-018-0147-2.

37. Kar, Y., G. Bozkurt, G., Yalman, Y. (2019). Liquid fuels from used transformer oil by catalytic cracking using bentonite catalyst. Environmental Progress and Sustainable Energy, 38, 4, 1-6, DOI: 10.1002/ ep.13080.

38. Wu, L., Wei, T. Y., Tong, Z. F., Zou, Y., Lin, Z. J., Sun, J. H. (2016) Bentonite-enhanced biodiesel production by $\mathrm{NaOH}$-catalyzed transesterification of soybean oil with methanol. Fuel Processing Technology, 144, 334-340, DOI: 10.1016/j.fuproc.2015.12.017.

39. Wu, Q., Qiang, T. C., Zeng, G., Zhang, H., Huang, Y., Wang, Y. (2017). Sustainable and renewable energy from biomass wastes in palm oil industry: A case study in Malaysia. International Journal of Hydrogen Energy, 42, 37, 23871-23877, DOI: 10.1016/j. ijhydene.2017.03.147. 
40. Hidayat, N., Suhartini, S., Utami, R. N., Pangestuti, M.B. (2020). Anaerobic digestion of fungally pre-treated oil palm empty fruit bunches: Energy and carbon emission footprint. IOP Conference Series: Earth and Environmental Science, 524, 1, DOI: 10.1088/1755-1315/524/1/012019.

41. Ariffin, M. A., Wan Mahmood, W. M. F., Harun, Z., Mohamed, R. (2017). Medium-scale gasification of oil palm empty fruit bunch for power generation. Journal of Material Cycles and Waste Management, 19, 3, 1244-1252, DOI: 10.1007/s10163-016-05188.

42. Li, Y. H., Chen, H. H. (2018). Analysis of syngas production rate in empty fruit bunch steam gasification with varying control factors. International Journal of Hydrogen Energy, 43, 2, 667-675, DOI: 10.1016/j. ijhydene.2017.11.117.

43. Monir, M. U., Aziz, A. A., Vo, D. V. N., Khatun, F. (2020). Enhanced Hydrogen Generation from Empty Fruit Bunches by Charcoal Addition into a Downdraft Gasifier. Chemical Engineering Technology, 43, 4, 762-769, DOI: 10.1002/ceat.201900547.

44. Aprianti, N., Faizal, M., Said, M., Nasir, S. (2020). Valorization of palm empty fruit bunch waste for syngas production through gasification. Journal of Ecological Engineering, 21, 7, 17-26, DOI: $10.12911 / 22998993 / 125461$.

45. Anisimov, P. N., Onuchin, E. M., Vishnevskaya, M. M., Nikolaevich, S. J., Andreeevich, M. A. (2016). The study of biomass moisture content impact on the efficiency of a power-producing unit with a gasifierand the stirling engine. Journal of Applied Engineering Science, 14, 3, 401-408, DOI: 10.5937/ jaes14-11010.

46. Oveisi, E., Sokhansanj, S., Lau, A., Lim, J., Bi, X., Preto, F., Mui, C. (2018). Characterization of recycled wood chips, syngas yield, and tar formation in an industrial updraft gasifier. Environments, 5, 7, 1-13, DOI: 10.3390/environments5070084.

47. Valdes, C. F., Marrugo, G., Chejne, F., Montoya, J. I., Gómez, C. A. (2015). Pilot-scale fluidized-bed co-gasification of palm kernel shell with sub-bituminous coal. Energy and Fuels, 29, 9, 5894-5901, DOI: 10.1021/acs.energyfuels.5b01342.

48. Shahbaz, M., Yusup, S., Inayat, A., Ammar, M., Patrick, D. O., Pratama, A., Naqvi, S. R. (2017). Syngas production from steam gasification of palm kernel shell with subsequent $\mathrm{CO} 2$ capture using $\mathrm{CaO}$ sorbent: An aspen plus modeling. Energy and Fuels, 31, 11, 12350-12357, DOI: 10.1021/acs.energyfuels. $7 \mathrm{~b} 02670$.

49. Monir, M. U., Aziz, A. A., Kristanti, R. A., Yousuf, A. (2020). Syngas production from co-gasification of forest residue and charcoal in a pilot scale downdraft reactor. Waste and Biomass Valorization, 11, 2, 635-651, DOI: 10.1007/s12649-018-0513-5.
50. Isworo, Y. Y., Kim, G. M., Jeong, J. W., Jeon, C. H. (2020). Evaluation of torrefied empty fruit bunch (EFB) and kenaf combustion characteristics: Comparison study between EFB and kenaf based on microstructure analysis and thermogravimetric methods. Energy and Fuels, 34, 6, 7094-7104, DOI: 10.1021/acs.energyfuels.9b04380.

51. Nyakuma, B. B., Wong, S., Oladokun, O. (2019). Non-oxidative thermal decomposition of oil palm empty fruit bunch pellets: fuel characterisation, thermogravimetric, kinetic, and thermodynamic analyses. Biomass Conversion and Biorefinery, DOI: 10.1007/s13399-019-00568-1.

52. Monir, M. U., Aziz, A. A., Kristanti, R. A., Yousuf, A. (2018). Co-gasification of empty fruit bunch in a downdraft reactor: A pilot scale approach. Bioresource Technology Reports, 1, 39-49, DOI: 10.1016/j.biteb.2018.02.001.

53. Martinez, L. V., Rubiano, J. E., Figueredo, M., Gomez, M. F. (2020). Experimental study on the performance of gasification of corncobs in a downdraft fixed bed gasifier at various conditions. Renewable Energy, 148, 1216-1226, DOI: 10.1016/j. renene.2019.10.034.

54. Iryani, D. A., Kumagai, S., Nonaka, M., Sasaki, K., Hirajima, T. (2017). Characterization and Production of Solid Biofuel from Sugarcane Bagasse by Hydrothermal Carbonization. Waste and Biomass Valorization, 8, 6, 1941-1951, DOI: 10.1007/s12649-0179898-9.

55. Gautam, N., Chaurasia, A. (2020). Study on kinetics and bio-oil production from rice husk, rice straw, bamboo, sugarcane bagasse and neem bark in a fixed-bed pyrolysis process. Energy, 190, 116434, DOI: 10.1016/j.energy.2019.116434.

56. Rout, T., Pradhan, D., Singh, R. K., Kumari, N. (2016). Exhaustive study of products obtained from coconut shell pyrolysis. Journal of Environmental Chemical Engineering, 4, 3, DOI: 10.1016/j.jece.2016.02.024.

57. Terzic, A., Pezo, L., Andric, L., Pavlovic, V. B., Mitic, V. V. (2017). Optimization of bentonite clay mechano-chemical activation using artificial neural network modeling. Ceramics International, 43, 2, 2549-2562, DOI: 10.1016/j.ceramint.2016.11.058.

58. Taher, T., Rohendi, D., Mohadi, R., Lesbani, A. (2019). Congo red dye removal from aqueous solution by acid-activated bentonite from sarolangun: kinetic, equilibrium, and thermodynamic studies. Arab Journal of Basic and Applied Sciences, 26, 1, 125136, DOI: 10.1080/25765299.2019.1576274. 
59. Chaudhuri, S. D., Mandal, A., Dey, A., Chakrabarty, D. (2020). Tuning the swelling and rheological attributes of bentonite clay modified starch grafted polyacrylic acid based hydrogel. Applied Clay Science, 185, 105405, DOI: 10.1016/j.clay.2019.105405.

60. Zhu, J., Zhang, P., Qing, Y., Wen, K., Su, X., Ma, L., Wei, J., Liu, H., He, H., Xi, Y. (2017). Novel intercalation mechanism of zwitterionic surfactant modified montmorillonites. Applied Clay Science, 141, 265271, DOI: 10.1016/j.clay.2017.03.002.

61. Aminy, D. E., Mudasir, M., Rusdiarso, B. (2020). Immobilization of dithizone on natural bentonite as adsorbent of $\mathrm{Cd}(\mathrm{II})$ ion. Key Engineering Materials, 840, 22-28, DOI: 10.4028/www.scientific.net/ kem.840.22.

62. Chen, Z., Gao, S., Xu, G. (2017). Simultaneous production of $\mathrm{CH} 4$-rich syngas and high-quality tar from lignite by the coupling of noncatalytic/catalytic pyrolysis and gasification in a pressurized integrated fluidized bed. Applied Energy, 208, 1527-1537, DOI: 10.1016/j.apenergy.2017.08.227.

63. Oliveira, A, d. N. d., Lima, M. A. B. d., Pires, L. H. d. O., Silva, M.R. d., Luz, P. T. S. d., Angelica, R. S., Filho, G.N.R., Costa, C. E. F., Luque, R., Nascimento, L. A. S. d. (2019). Bentonites modified with phosphomolybdic heteropolyacid (HPMo) for biowaste to biofuel production. Materials, 12, 9, DOI: 10.3390/ ma12091431.
64. Han, T., Ding, S., Yang, W., Jönsson, P. (2019). Catalytic pyrolysis of lignin using low-cost materials with different acidities and textural properties as catalysts. Chemical Engineering Journal, 373, 846-856, DOI: 10.1016/j.cej.2019.05.125.

65. Gao, X., Zhong, H., Yao, G., Guo, W., Jin, F. (2016). Hydrothermal conversion of glucose into organic acids with bentonite as a solid-base catalyst. Catalysis Today, 274, 49-54, DOI: 10.1016/j.cattod.2016.02.008.

66. Yang, W. S., Lee, J. S., Park, S. W., Kang, J. J., Alam, T., Seo, Y. C. (2016). Gasification applicability study of polyurethane solid refuse fuel fabricated from electric waste by measuring syngas and nitrogenous pollutant gases. Journal of Material Cycles and Waste Management, 18, 3, 509-516, DOI: 10.1007/s10163-016-0512-1.

67. Li, Z., Xu, H., Yang, W., Zhou, A., Xu, M. (2019). CFD simulation of a fluidized bed reactor for biomass chemical looping gasification with continuous feedstock. Energy Conversion and Management, 201, 112143, DOI: 10.1016/j.enconman.2019.112143.

68. Park, S. W., Lee, J. S., Yang, W. S., Alam, M. T., Seo, Y. C. (2020). A comparative study of the gasification of solid refuse fuel in downdraft fixed bed and bubbling fluidized bed reactors. Waste and Biomass Valorization, 11, 2345-2356, DOI: 10.1007/s12649018-0431-6. 